\title{
Morphology of the Aging Forehead: A Three- Dimensional Computed Tomographic Study
}

\author{
Hyung Suk Yi \\ Department of Plastic and Reconstructive \\ Surgery, Kosin University College of Medicine, \\ Busan, Korea
}

No potential conflict of interest relevant to this article was reported.

\begin{abstract}
Background: Age-related changes have been studied for lower and middle facial bones. Although the forehead comprises one-third of the facial area, no studies have investigated age-related changes in the upper part of the face or forehead. The purpose of this study was to use three-dimensional computed tomography (3D CT) to investigate age-related changes in the frontal bone.

Methods: A retrospective review was performed for patients who underwent 3D CT scan of facial bones. Patients were divided by gender and age (20 to 40 years, 41 to 60 years, and above 60 years). The frontal bone curvature was evaluated by the length of frontal bone and by two frontal bone angles in relation to the Frankfurt horizon.

Results: In both genders, aging was associated with increasing lower slope length. In elderly men (>60 years), the upper slope angle was significantly higher when compared to younger male subjects. Women demonstrated similar age-related changes, but the differences were only statistically significant for the middle and older age groups.

Conclusion: This study demonstrates quantifiable age-related changes in the frontal bone. These findings contribute to the understanding of age-related changes of the facial soft tissues. The mean measurements in each age group can be used as a reference when planning forehead reconstruction.
\end{abstract}

Keywords: Forehead / Frontal bone / Aging / Three-dimensional computed tomography

\section{INTRODUCTION}

The forehead represents the upper third of the face. Unlike the middle and lower face, this upper portion lacks distinct features that constitutes the face and has a geometrically simple curvature, which is a reflection of the underlying frontal bone. Defects in the frontal bone are usually responsible for unsatisfactory cosmesis in the forehead, and the need for and method of reconstruction depends on the type and extent of bony defect $[1,2]$.

In frontal bone defects, the overall contour can be derived from the surrounding frontal bone defect. However, such redundancy of geometric information might not be available for large defects and comminuted fractures. Additionally, frontal bone convexity is known to vary between genders and with age [3].

In profile view of forehead, there are no obvious anatomical landmarks except for glabella and trichion. However, the convexity has a geometric arrangement with a peak point of prominence. This point is a perpendicular peak point from a line drawn between gabella and trichion and represents the point of inflection in the forehead curvature (Fig. 1). In this study, we investigate normative forehead cephalometry in Korean patients using facial three-dimensional computed tomography (3D CT) images.

\section{METHODS}

Department of Plastic and Reconstructive Surgery, Kosin University College of Medicine, 262 Gamcheon-ro Seo-gu, Busan 49267, Korea

E-mail: sencha21@naver.com

Received May 18, 2015 / Revised July 15, 2015 / Accepted August 4, 2015
A single-institutional retrospective review was performed for all 

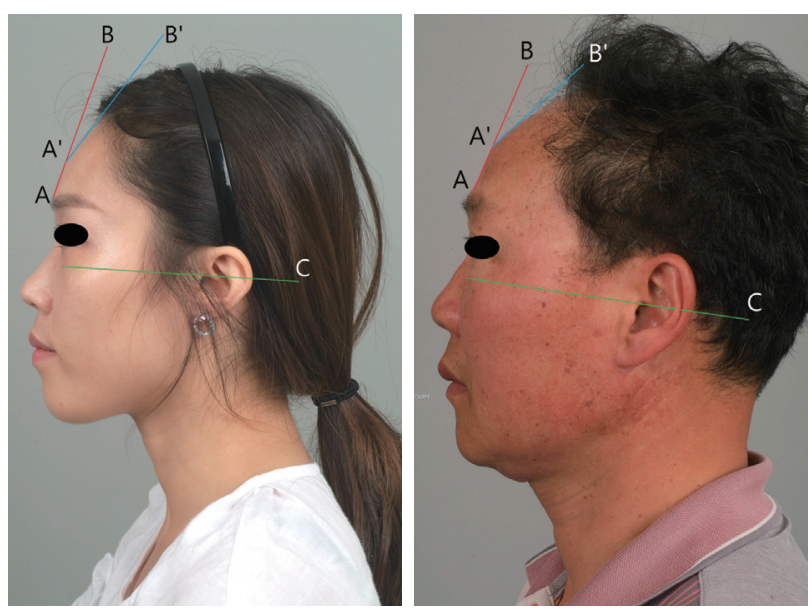

Fig. 1. Profile view. A straight line is drawn from the superior border of the glabella (Line AB) along the curvature of the forehead. A line is drawn along the surface of the curvature of the forehead from the point of large change in angle (between lines $\mathrm{AB}$ and $\mathrm{A}^{\prime} \mathrm{B}$ ').

patients who had underwent facial bone CT imaging between February of 2010 and February of 2015. Patients were excluded for presence of zygomatic fracture, frontal bone fracture, or craniofacial anomaly (congenital or otherwise). Medical records were reviewed for demographic information, and patients were grouped by age ( 21 to 40,41 to 60 , and older than 61 years) and by gender. Each of the age/gender groups consisted of 30 randomly selected patients who met both the study inclusion criteria and appropriate age and gender. In total, 180 patients were included for retrospective analysis.

Each CT study was loaded as a 3-dimensional reconstruction into PACS program (M-view, version 5.4. Marotech, Seoul). Under a left lateral orthogonal view, the Frankfurt horizontal (FH) plane was identified and used as a reference line. The forehead was divided into upper and lower slopes. The lower portion was defined by a tangential line $(\mathrm{AB})$ that began at the supraorbital ridge. The upper portion was defined by another tangential line $\left(\mathrm{A}^{\prime} \mathrm{B}^{\prime}\right)$, which began at the point of inflection $\left(A^{\prime}\right)$. Both of these lines ( $A B$ and $\left.A^{\prime} B^{\prime}\right)$ were used to find the respective angles to the FH plane. Furthermore, the length of lower slope was measured between points A and A'(Fig. 2).

\section{Statistical analysis}

For both genders, at-test was used to identify trends across the age groups (young versus middle age, middle age versus old) with re-

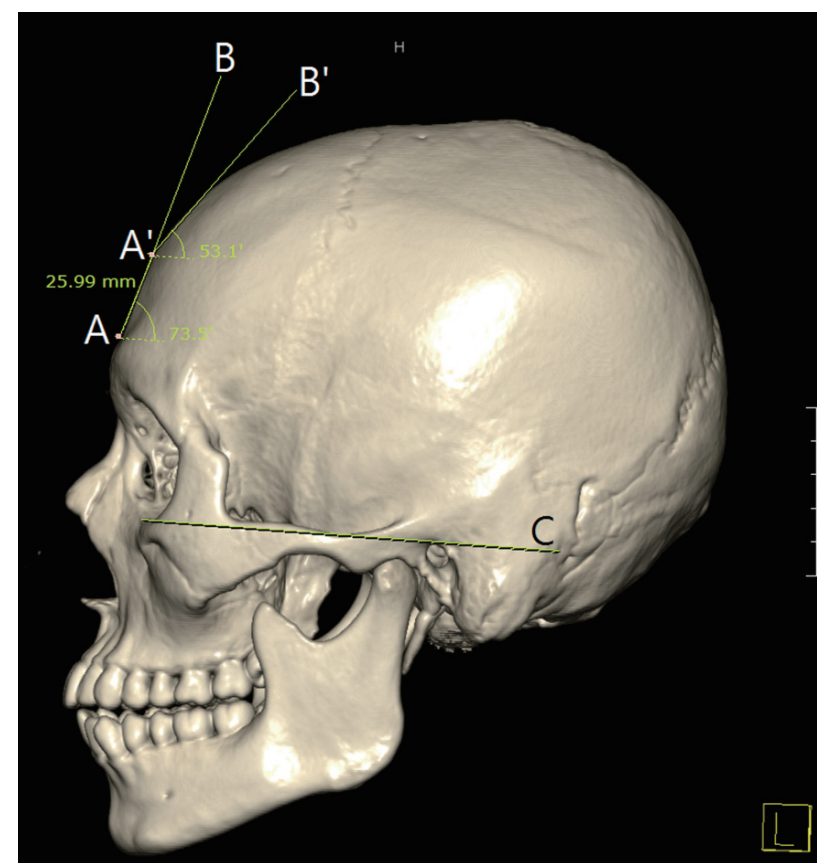

Fig. 2. Under a left lateral orthogonal view, the Frankfurt horizontal (Line C) plane was identified and used as a reference line. The forehead was divided into upper and lower slopes. The lower portion was defined by a tangential line (Line $\mathrm{AB}$ ) that began at the supraorbital ridge. The upper portion was defined by another tangential line (Line $\left.A^{\prime} B^{\prime}\right)$ which began at the point $\left(A^{\prime}\right)$ where the forehead curvature showed significant deviation from the lower slope. Both of these lines (Lines $\mathrm{AB}$ and $\mathrm{A}^{\prime} \mathrm{B}$ ') were used to find the respective angles to the $\mathrm{FH}$ plane. Furthermore, the length of lower slope was measured between points $A$ and A'. In this 22-year-old male patient, the lower and upper slope angles were 73.5 and 53.1 degrees with respect to the Frankfurt horizontal line, with a lower slope length of $25.99 \mathrm{~mm}$.

sults considered significant at a value of $p<0.05$. All statistical analyses were performed with IBM SPSS Statistics ver. 20.0 (IBM, Armonk, NY, USA).

\section{RESULTS}

\section{Male}

The mean age of young male group was 26.97 years. The mean lower slope angle was 72.54 degrees and ranged between 64.34 to 80.96 degrees. The mean upper slope angle was 52.87 degrees and ranged from 47.84 to 63.43 degrees. The mean length of lower slope was $26.79 \mathrm{~mm}$ and ranged between $19.46 \mathrm{~mm}$ and $33.28 \mathrm{~mm}$. The mean age of the middle age group was 49.83 years. The mean lower slope angle of this group was 76.64 degrees, and the mean upper 
slope was 54.97 degrees. The mean length of lower slope was 24.64 $\mathrm{mm}$. The lower slope angle measurements ranged from 69.4 to 83.1 degrees, the upper slope ranged from 43.4 to 63 degrees, and the lengths were 12.48 to $30.16 \mathrm{~mm}$. The mean age of the old age group was 30.43 years. The mean lower slope angle was 39.9 degrees, and the mean upper slope angle was 57.43 degrees. The mean length of lower slope was $22.75 \mathrm{~mm}$. The lower slope angle measurements ranged from 73.9 to 89.3 degrees, the upper slope ranged from 51.2 to 65.3 degrees, and the lengths of lower slopes were 15.02 to 28.18 $\mathrm{mm}$ The lower and upper slope angles increased significantly with increasing age, whereas length of lower slope decreased with age, and these results were statistically significant (Table 1, Figs. 3, 4).

\section{Female}

The mean age of the young female group was 28.53 years. The mean angle of the lower slope was 76.90 degrees and ranged from 68.25 to 83.53 degrees. The mean angle of the upper slope was 55.91 degrees and ranged from 51.5 to 61.8 degrees. The mean

Table 1. Frontal bone geometry in male subjects

\begin{tabular}{lccc} 
Factor & $\begin{array}{c}\text { Young age } \\
\text { group }\end{array}$ & $\begin{array}{c}\text { Middle age } \\
\text { group }\end{array}$ & $\begin{array}{c}\text { Old age } \\
\text { group }\end{array}$ \\
\hline Lower slope angle $\left(^{\circ}\right)$ & 72.54 & $76.64^{\text {a) }}$ & $79.90^{\text {b) }}$ \\
\hline Upper slope angle $\left(^{\circ}\right)$ & 52.87 & $54.97^{\text {a) }}$ & $57.43^{\text {b) }}$ \\
\hline Length of lower slope $(\mathrm{mm})$ & 26.79 & $24.64^{\text {c) }}$ & $22.75^{\text {d) }}$ \\
\hline
\end{tabular}

a) Statistically significant increase from young to middle age groups $(p<0.001$, $p=0.04) ;{ }^{\text {b) }}$ Statistically significant increase from middle to old age groups $(p=0.003, p=0.032)$; ${ }^{c}$ Statistically significant decrease from young to middle age groups $(p=0.035)$; ${ }^{d}$ Statistically significant decrease from middle to old age groups $(p=0.033)$. length of lower slope was $24.73 \mathrm{~mm}$, and ranged from 19.25 to $28.75 \mathrm{~mm}$. The mean age of the middle age group was 48.53 years. The mean angle of the lower slope was 79.37 degrees, the mean angle of the upper slope was 57.55 degrees, and the mean length of lower slope was $24.06 \mathrm{~mm}$. These measurements ranged from 71.6 to 88.48 degrees, 17.75 to 28.45 degrees, and 17.75 to $28.45 \mathrm{~mm}$, respectively. The mean age of the old age group was 71.77 years, and the mean angles of the lower and the upper slopes were 81.72 degrees and 60.86 degrees, respectively. The mean length of lower slope was $22.53 \mathrm{~mm}$, the lower slope angle ranged from 74.6 to 88.7 degrees, the upper slope ranged from 52.5 to 68.9 degrees, and the length of lower slope ranged from 18.19 to $27.39 \mathrm{~mm}$. The size of the lower slope angle significantly increased with age. The angle of the upper slope also increased with age in the male patient groups, but this was not statistically significant between the young and middle age groups. However, there was a significant increase in this angle in the old age group compared to the young and middle age groups. The length of lower slope tended to decrease with age, but this was only statistically significant in the old age group compared to the young and middle age groups (Table 2, Figs. 3, 4).

\section{DISCUSSION}

The forehead comprises one-third of the face and is important from both cosmetic and functional perspectives. The shape of forehead is determined by the frontal bone, which supports the soft tissue. Previous studies have reported the use of prosthesis or a fat
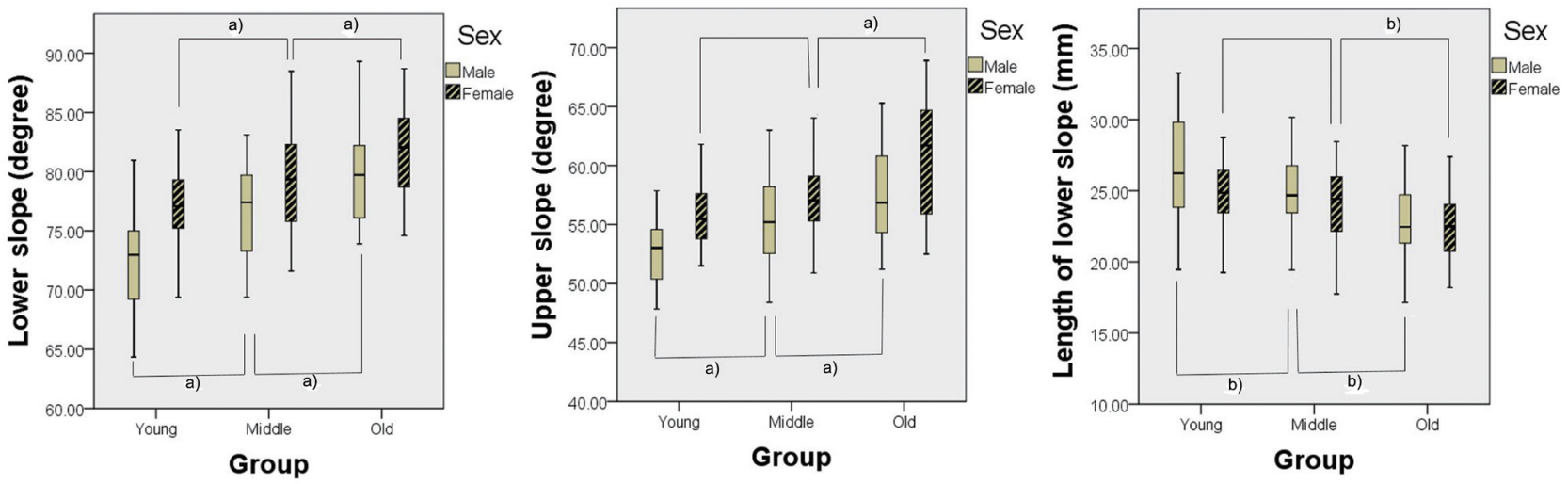

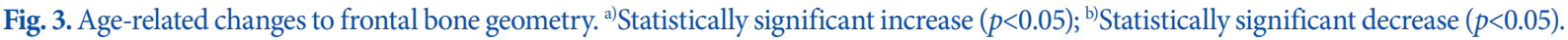



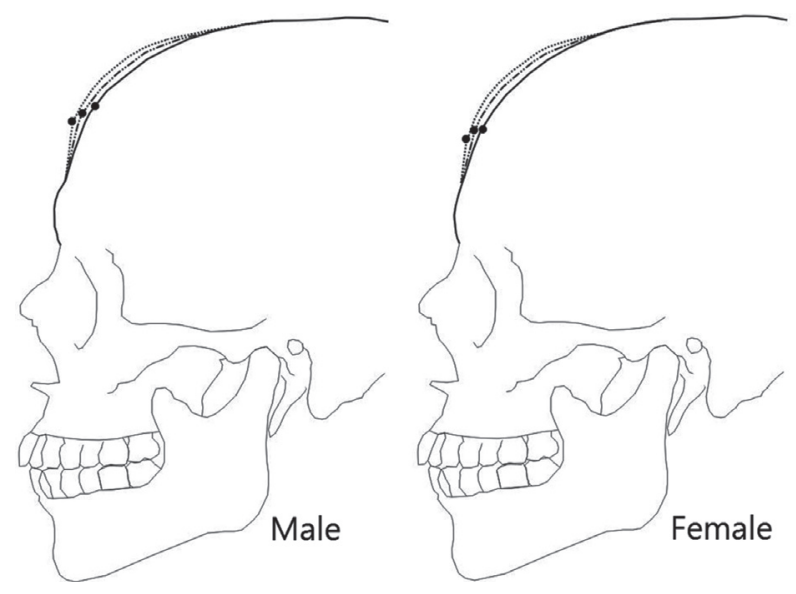

Fig. 4. The age-related frontal bone changes in male and female subjects. Solid lines represent younger age group (20-40 years). Dashdot-dot lines represent middle age group (41-60 years). Dotted lines represent older age group ( $>60$ years). The block dots represent the mean position of inflection in frontal bone curvature (Point A').

Table 2. Frontal bone geometry in female subjects

\begin{tabular}{lccc} 
Factor & $\begin{array}{c}\text { Young age } \\
\text { group }\end{array}$ & $\begin{array}{c}\text { Middle age } \\
\text { group }\end{array}$ & $\begin{array}{c}\text { Old age } \\
\text { group }\end{array}$ \\
\hline Lower slope angle $\left(^{\circ}\right)$ & 76.9 & $79.37^{\mathrm{a})}$ & $81.72^{\mathrm{b})}$ \\
Upper slope angle $\left(^{\circ}\right)$ & 55.91 & 57.55 & $60.86^{\mathrm{b})}$ \\
\hline Length of lower slope $(\mathrm{mm})$ & 24.73 & 26.04 & $22.53^{\mathrm{c}}$ \\
\hline
\end{tabular}

a) Statistically significant increase from young to middle age groups $(p=0.024)$;

b) Statistically significant increase from middle to old age groups ( $p=0.029$, $p=0.004)$; ${ }^{c}$ Statistically significant decrease from middle to old age groups $(p=0.025)$.

graft to attempt to correct or improve the forehead cosmesis $[4,5]$.

In the past, forehead profile was most frequently evaluated using clinical and/or photographic cephalometry. With recent advancements in 3D CT technology, however, acquisition of objective cephalometric data became a widespread phenomenon in both clinical and research settings, with 3D CT studies demonstrating reliability and accuracy similar to traditional methods of cephlometry [6].

Three-dimentional CT studies have been useful in understanding age-related changes in the facial bone and soft tissue [7]. By comparing CT studies across age groups, Shaw Jr, et al. have demonstrated that the width of facial skeleton and area of orbital aperture increase and glabella and maxillary angles decrease with age [8]. However, much of these 3D CT based studies have focused on the middle and lower parts of the face [8-11].

In this study, we have investigated the forehead of 180 Korean patients who had undergone 3D CT studies for various indications but without any identifiable pathology or injury. A distinct cephalometric difference was observed between male and female patients. Compared to female patients, male patients tended to have a longer forehead, with both lower and upper slope angles being shallower. All of this indicates that, generally, masculine foreheads tend to be taller and have a more abrupt retrograde slope with the converse pattern characterizing the feminine forehead.

In both genders, aging was associated with increasing lower slope length, which might be due to the age-related volume loss in the frontal sinus [12]. In elderly men (>60 years), the upper slope angle was significantly higher when compared to younger male subjects. Wrinkles in the forehead are caused by repeated deformation of the skin from facial expressions and by decreased skin tension [7]. The age-related decrease in length and angle of lower frontal bone might be related to the decreased support of the forehead soft tissues.

At the present moment, normative anthropometric criteria do not exist for the forehead. Generally, forehead aesthetics is assessed by the ratio of forehead to the whole face, which determines whether a forehead is considered to wide or narrow on frontal view. Such assessment is useful for hair removal or transplant but cannot be used to guide frontal bone reconstruction. The curvature and prominence of a forehead is evaluated from the lateral view, and should be described by a method that can be obtained and analyzed in a standard manner, as we have attempted in this study.

There are three limitations to this study. First, this study focused on age-related changes to the frontal bone but did not evaluate the soft tissue covering the frontal bone. Further analysis of the soft tissue using 3D scanners should provide additional understanding of age-related changes to the forehead. Second, the study was limited to ethnic Korean population and will need validation in other populations. The elderly subjects in our study had grown up in post-Korean War era, with poor nutrition a potential confounding factor. Finally, the forehead curvature was estimated using two straight lines in reference to Frankfurt horizontal plane. A more optimal method of assessing this curvature would involve complex mathematical models, which may not be easy to apply in the clinical context. 
The most important aspect of forehead aesthetics is the extent of prominence as viewed from the side. This data is helpful in preoperative planning of patients wishing for prosthetic implantation of the forehead, as normative values are available for each age group. In addition, the study results can be used for planning and evaluating frontal bone defect reconstruction for comminuted fractures or tumor resection. Further studies are needed to evaluate for interobserver reliability.

\section{REFERENCES}

1. Chen TM, Wang HJ, Chen SL, Lin FH. Reconstruction of post-traumatic frontal-bone depression using hydroxyapatite cement. Ann Plast Surg 2004;52:303-8.

2. Uemura T, Sawai K, Kikuchi M, Masuoka J, Matsushima T. Technical strategies for en bloc resection and immediate reconstruction in hemangioma of the frontal bone. J Craniofac Surg 2014;25:e402-3.

3. Spiegel JH. Facial determinants of female gender and feminizing forehead cranioplasty. Laryngoscope 2011;121:250-61.

4. Kang JH, Jung SW, Lee YH, Kook KS. Contouring of forehead and temple area with auto-fat injection. J Korean Soc Plast Reconstr Surg 2011;38:166-72.
5. Park DK, Song I, Lee JH, You YJ. Forehead augmentation with a methyl methacrylate onlay implant using an injection-molding technique. Arch Plast Surg 2013;40:597-602.

6. Oh S, Kim CY, Hong J. A comparative study between data obtained from conventional lateral cephalometry and reconstructed three-dimensional computed tomography images. J Korean Assoc Oral Maxillofac Surg 2014;40:123-9.

7. Mendelson $\mathrm{B}$, Wong $\mathrm{CH}$. Anatomy of the aging face. In: Rodriguez ED, Losee JE, Neligan PC, editors. Plastic surgery. Edinburgh: Saunders; 2012.p.78-92

8. Shaw RB Jr, Kahn DM. Aging of the midface bony elements: a threedimensional computed tomographic study. Plast Reconstr Surg 2007;119:675-81.

9. Pessa JE, Slice DE, Hanz KR, Broadbent TH Jr, Rohrich RJ. Aging and the shape of the mandible. Plast Reconstr Surg 2008;121:196-200.

10. Shaw RB Jr, Katzel EB, Koltz PF, Kahn DM, Girotto JA, Langstein HN. Aging of the mandible and its aesthetic implications. Plast Reconstr Surg 2010;125:332-42.

11. Shaw RB Jr, Katzel EB, Koltz PF, Yaremchuk MJ, Girotto JA, Kahn DM, et al. Aging of the facial skeleton: aesthetic implications and rejuvenation strategies. Plast Reconstr Surg 2011;127:374-83.

12. Tatlisumak E, Ovali GY, Asirdizer M, Aslan A, Ozyurt B, Bayindir P, et al. CT study on morphometry of frontal sinus. Clin Anat 2008;21: 287-93. 